\title{
Resenhas
}

\section{Propriedade intelectual e política externa: o Brasil no contexto internacional}

VIGEVANI, Tullo. O Contencioso Brasil x Estados Unidos da Informática: uma análise sobre formulação da política exterior. São Paulo: AlfaOmega, Editora da Universidade de São Paulo, 1995, 349 p.

VARELLA, Marcelo Dias. Propriedade intelectual de setores emergentes: biotecnologia, fármacos e informática. São Paulo: Atlas, 1996, 255 p.

O objetivo do livro de Tullo Vigevani está colocado claramente pelo autor em sua introdução: estudar uma questão de grande relevância intrínseca para a inserção econômica internacional do Brasil-a disputa “informática”, na verdade uma disputa de poder, entre o Brasil e os Estados Unidos - e refletir sobre pontos fundamentais para as relações internacionais contemporâneas. Buscou o autor, com muita proficiência, "ampliar a compreensão de como são tomadas as decisões no Brasil no que se refere à política exterior”. Devo confessar, como acadêmico em tempo parcial e diplomata em tempo integral, que sempre me interroguei sobre a validade propriamente científica, a coerência argumentativa e a legitimidade heurística dos estudos tipicamente acadêmicos sobre mecanismos de tomada de decisão em política internacional ena política externa brasileira em particular. Os pesquisadores universitários geralmente partem de um modelo teórico e de um esquema conceitual muito bem construídos, passam a entrevistar diplomatas e outros atores relevantes numa análise de caso bem delimitado e terminam por tirar conclusões sobre a “eficácia weberiana” de seu tipo-ideal de processo decisório, no caso aplicado a um exemplo concreto das relações políticas entre as nações.

Os resultados costumam ser insatisfatórios ou frustrantes, seja porque o pesquisador parte de um modelo de racionalidade ideal de conduta diplomática que não costuma encontrar-se na realidade, seja porque os próprios atores racionalizam a posteriori sua atuação no caso, de molde a justificar os resultados alcançados, “que só poderiam ser” aqueles efetivamente obtidos. Como diriam os franceses, CQFD, ou seja, eis o que era preciso demonstrar. Não éo caso, devo logo adiantar, deste precioso estudo sobre mecanismos de decisão aplicados ao caso do contencioso informático entre o Brasil eseu principal parceiro ocidental, o império norte-americano da informática. 
Trata-se, em primeiro lugar, de uma descrição absolutamente fiel de todos os aspectos envolvidos no famoso contencioso bilateral: política nacional de informática, presença norte-americana no mercado brasileiro e internacional, decisões do governo brasileiro, negociações diplomáticas em várias fases, implicações econômicas, políticas e diplomáticas do setor, enfim, o universo completo dos elementos em jogo, l'enjeu, como ainda diriam os franceses; assistese, em segundo lugar, a uma riquíssima discussão sobre as virtudes e limitações da política externa nacional in motion, isto é, tal como construída e defendida no próprio processo de sua constituição por responsáveis governamentais, dirigentes políticos, líderes empresariais e, of course, pelos próprios diplomatas do Itamaraty, atores relevantes neste case study.

O resultado é propriamente brilhante: Tullo Vigevani soube captar com rara acuidade para um "observador externo" - mas talvez um espectador politicamente motivado, o que em nada diminui sua objetividade acadêmica e sua imparcialidade de julgamento - todos os matizes de uma difícil questão que contaminou durante a segunda metade dos anos 80 as relações políticas e mesmo econômicas entre os dois maiores países do hemisfério ocidental. O problema transcedeu a esfera propriamente bilateral pois que, nessa época, ambos os países eram atores relevantes durante a primeira fase, já bastante complicada politicamente por força das ambiguidades da Declaração de Punta del Este, das negociações comerciais multilaterais da Rodada Uruguai.Aessetítulo, a “estória” do contencioso contida neste livro vale pelo que ele de fato é: um registro histórico meritório sobre uma queda de braço diplomático - que prestou-se, diga-se de passagem, a muitas bravatas ideológicas e posturas desafiadoras da parte de certos atores nos dois países - e uma interpretação "acadêmica” (no bom sentido da palavra) verdadeiramente inovadora das condicionantes internas e externas que atuam na política internacional do Brasil. Nesta segunda vertente, a obra vai além de "um” estudo do "caso" da informática para penetrar no próprio modo de funcionamento da diplomacia brasileira e, por que não?, do próprio Estado enquanto burocracia organizada (no caso brasileiro, com as ressalvas conhecidas ao confuso processo pós-1985 de desmantelamento do período militar e de inauguração de uma nova fase política nacional).

Precisamente por isso, o livro é talvez mais útil do ponto de vista metodológico do que propriamente enquanto racconto storico - o que de toda forma ele o faz, de maneira excelente-sobre um “banal” incidente diplomático que figurará como parágrafo marginal noslivros dehistória das relações diplomáticas do Brasil (e sequer entrará nos records da história diplomática do império). Como evidencia o Embaixador Rubens Ricupero na apresentação da contracapa, Tullo Vigevani ilumina as causas internas e externas do caso exemplar da informática 
e demonstra a “dificuldade de consolidaruma política num contexto internacional conturbado, quando as bases de sustentação dessa política vão se debilitando, sem surgir qualquer outra alternativa”. No caso em espécie, a conceituação de "política” acima mencionada pode referir-se tanto à interna como à externa, já que o Brasil vivia então um período excepcional de transição entre o velho modelo substitutivo de desenvolvimento industrial e tecnológico e um novo, ainda não totalmente configurado (aspecto híbrido representado precisamente pela política nacional de informática), entre um Estado dirigista herdado do recente passado militar e um novo Estado (neo-populista?, social-democrático?, pretensamente reformista?, modestamente amorfo?), entre uma política externa razoavelmente consensual e inovativamente catalogada até então (pragmatismo responsável, diplomacia ecumênica) e uma fase de incertezas na forma e na substância da atuação internacional do País.

Como diz ainda Vigevani, "as eventuais fortunas da política externa se assemelham em grande medida às sortes da política em geral”, concluindo, de forma lúcida, que a "exigüidade dos espaços democráticos institucionais [para a discussão ampla de problemas relevantes de política interna e externa como o da informática] talvez seja uma das razões da dificuldade em definir estratégias, partindo de um reconhecimento bem fundamentado das relações de poder efetivamente existente". Essa dificuldade, diz ainda nosso autor, "foi claramente detectada na reconstrução histórica do contencioso”. Nesse sentido, o contencioso informático é exemplar, uma vez que ele evidencia a falta, "na sociedade e no Estado brasileiros, de um acompanhamento sistemático das relações internacionais".

Olivro de Tullo Vigevani vem precisamente suprir uma dessas lacunas, ao contribuir significativamente para uma discussão fundamentada das questões nele enfocadas nos meios acadêmicos, empresariais e governamentais. Como tal, ele deveria ser adotado como leitura “obrigatória” no ensino de história diplomática, de política exterior ou de relações internacionais nos cenáculos universitários ena própria academia diplomática oficial. Sua contribuição para o estudo “prático” dessas disciplinas, assim como para uma teoria, vera e própria, das "relações internacionais do Brasil”, étanto mais relevante que a análise do caso informático é enfeixado e precedido por cinco capítulos dedicados ao exame e discussão das teorias históricas e políticas sobre relações internacionais contemporâneas. É aqui, entre outras passagens, onde Tullo Vigevani revela o melhor de seu “renascentismo” intelectual, discutindo desde Hobbes, Rousseau e Kant até Morgenthau, Aron, Kehoane, Rosecrance, Gilpin e Kennedy. Um livro para ser não apenas lido e anotado, mas saboreado e desfrutado com prazer por todos 
aqueles que se interessam por política externa e relações internacionais e por políticas públicas em geral.

A excelente obra de Marcelo Dias Varella, jovem pesquisador em Direito da Universidade de Viçosa, atualmente fazendo mestrado em Relações Internacionais em Santa Catarina, traça um panorama completo da proteção à propriedade intelectual nos setores de ponta da inventividade humana biotecnologia, químico-farmacêutica e software - e insere o sistema de proteção à tecnologia patentária do Brasil no quadro internacional. O livro está dividido em quatro partes bem caracterizadas: uma introdução históricofilosófica sobre a proteção à tecnologia proprietária e a evolução do sistema no Brasil, o patenteamento de processos e produtos da biotecnologia (inclusive os direitos do melhorista de cultivares e a questão dos microorganismos), uma terceira parte sobre produtos e processos da indústria farmacêutica e, finalmente a proteção intelectual de softwares; completam o volume três anexos sobre a legislação aplicável nos setores de biotecnologia e de informática e a convenção sobre diversidade biológica, ratificada pelo Brasil em 1995. A simples menção dessa cobertura temática diversificada numa área tão complexa como a propriedade intelectual de novas tecnologias dá uma idéia da riqueza do empreendimento de Varella e de sua pertinência política e econômica para um debate de alto nível sobre esses temas no Brasil, numa área ainda sujeita a preocupações alarmistas da opinião pública (com a chamada “manipulação dos seres vivos”, por exemplo) ou a impulsos românticos, muitas vezes irracionais econômica e socialmente, de ecologistas e “amigos” muito pouco científicos da Natureza.

Muito embora grande parte da discussão levada a cabo na obra também se refira ao contexto internacional e às pressões suportadas pelo Brasil de meados dos anos 80 a princípios dos 90, deve-se ler esse precioso livro pelos seus méritos próprios e não como uma espécie de suporte intelectual a um combate “antiimperialista” ou de resistência aos interesses “oligopólicos” dos grandes conglomerados químico-farmacêuticos do Primeiro Mundo. Aprincipal virtude do livro é, assim, dar um esteio intelectual e doutrinário, para não dizer científico, a uma correta compreensão da problemática social e econômica e do impacto tecnológico e propriamente político da proteção proprietária nos setores emergentes, permitindo ademais uma informação de boa qualidade sobre a natureza jurídico-econômica da nova legislação que foi introduzida recentemente no Brasil nesses campos (o Código da Propriedade Industrial de 1996, a lei de cultivares recém adotada e os debates continuados sobre a proteção de softwares). 
Como diz o próprio autor, os setores selecionados para análise, biotecnologia, indústria farmacêutica e informática, são os que "constituem células fundamentais do tecido econômico, político e social e (...) qualquer transformação por que passem, provocarão profundas modificações na própria sociedade". Ele procurou, assim, abordar os pontos "que geraram maiores dúvidas e controvérsias, tanto no Brasil, como em âmbito internacional”, esperando com isso "desmitificar tão propalado tema, que tem importante significado para o desenvolvimento nacional”. Deve-se reconhecer que Varella cumpriu inteiramente o prometido em sua introdução e seu livro pode desde já ser considerado como único no gênero no Brasil, não apenas porque escapa dos modelos no gênero (os habituais “comentários à lei brasileira de propriedade intelectual”), como também porque combina a análise desses diversos temas da tecnologia proprietária em setores emergentes com a precisão do jurista e a base técnica do cientista especializado.

Com efeito, a obra em nada se parece aos áridos comentários dos advogados especialistas em propriedade intelectual (que frequentemente nada mais fazem senão a exegese para o leigo do “juridiquês” inscrito nos textos legais), preferindo Varella discutir exaustivamente o contexto histórico-político e o quadro econômico-internacional no qual foi elaborado o sistema legal da propriedade intelectual, nos planos nacional e multilateral. O grande público brasileiro, geralmente dominado pelas informações jornalísticas sobre a "riqueza biológica” da floresta amazônica ou por um certo confusionismo "progressista" entre patenteamento farmacêutico e "soberania nacional”, não tem idéia da complexidade do debate internacional nessas áreas, do intenso trabalho dos acadêmicos e peritos de organizações intergovernamentais e das acirradas negociações diplomáticas em foros como a Organização Mundial da Propriedade Intelectual e o GATT-OMC.

O texto de Varella é meridianamente claro, tanto do ponto de vista técnico, como político-jurídico. Na primeira seção substantiva, por exemplo, ele se propõe "expor como se realiza a proteção intelectual de seres vivos, em destaque para plantas e organismos. Também objetivamos traçar os principais impactos das modalidades de proteção sobre o cenário econômico do desenvolvimento de novas pesquisas, sobre o meio ambiente e sobre a sociedade como um todo. No entanto, não poderíamos cumprir esta tarefa sem apresentar ao leitor os elementos necessários para a compreensão da realidade internacional da Biotecnologia”. Esse mesmométodo simples, objetivo ecompleto de introdução à discussão dos problemas da área se repete em cada uma das partes sobre os demais setores selecionados, como forma de introduzir sua contribuição 
verdadeiramente original: uma discussão cerrada das modalidades jurídicas das formas de proteção intelectual sobre plantas, fármacos e programas de computador, terminando com a descrição da legislação em vigor no Brasil e mesmo aquela que ainda estava em elaboração no momento da redação do texto (lei de cultivares, por exemplo).

Trata-se, sem dúvida alguma, da melhor introdução disponível no Brasil sobre os desafios atuais e futuros à sua inserção soberana no processo de globalização econômica, mais do que nunca dominado pela excelência da pesquisa e desenvolvimento nos setores emergentes. O cenário focalizado por Varella é ainda aquele no qual o Brasil procurava resistir - no GATT, na OMPI, no plano bilateral - às tendências cada vez mais restritivas de apropriação proprietária no campo das novas tecnologias: essa fase histórica correspondeu ao período inicial da Rodada Uruguai, marcado pela resistência defensiva do Brasil e da Índia às demandas “protecionistas” das grandes empresas multinacionais, quando paralelamente os Estados Unidos adotavam ilegalmente sanções unilaterais e retaliações econômico-comerciais contra o Brasil por sua atitude intransigente nessas áreas (recusa do patenteamento farmacêutico e biotecnológico, delonga na adoção de uma legislação sobre o software, discriminação nacionalista na área da informática, política industrial de reserva de mercado etc). Em 1990, afirma o autor, “o governo brasileiro cedeu e colocou como prioridade a formação de uma nova legislação tocante à propriedade intelectual. Nesta nova norma, pretendia-se abranger principalmente os reclames da indústria farmacêutica internacional e da indústria biotecnológica, que teve forte ascensão nos últimos anos”.

Pode-se concordar basicamente com esse tipo de interpretação, muito embora devam ser ainda considerados certos aspectos atinentes à própria inserção econômica internacional do Brasil e sua capacitação tecnológica nacional. Tem-se hoje como assente, por exemplo, que os anos (ou décadas) de não patenteamento farmacêutico ou de reserva de mercado da informática não foram especialmente beneficiosos em termos de acumulação de know-how ou de grandes investimentos em $P \& D$ laboratorial e industrial em química fina e em sistemas informáticos (hard e soft). O País formou, por certo, muitos engenheiros especializados em “tecnologia da informação”, mas nunca conseguiu ter uma fábrica de circuitos integrados, da mesma forma como ele multiplicou fábricas de vitaminas e de remédios genéricos, copiando muitos produtos não protegidos (et pour cause), sem ter logrado desenvolver, por razões compreensíveis, tecnologia própria em processos farmacêuticos. Um militante da causanacionalista certamente continua se posicionando contra o patenteamento farmacêutico, 
mas a postura dos pesquisadore acadêmicos é provavelmente mais matizada, não sendo de surpreender que uma maioria deles se coloque resolutamente a favor da proteção patentária (inclusive por óbvios motivos de apropriação de “rendas monopólicas”).

O País como um todo, por sua vez, precisa fazer uma espécie de tradeoff entre a proteção à tecnologia proprietária embutida numa legislação mais severa - e o pagamento de royalties que daí decorre - e a atração de novos investimentos, praticamente inevitáveis num país de grande mercado como éo Brasil. Sabe-se que a indústria farmacêutica é particularmente sensível à variável do patenteamento, em todos os países e circunstâncias econômicas, mas as decisões empresariais de investimento são mais adotadas por considerações típicas de mercado (dimensão, controle de preços, compras governamentais) do que especificamente pela disponibilidade da patente. Ainda assim, o quadro jurídico da proteção patentária é ele mesmo indutor de novos investimentos (sobretudo intelectuais) nos setores emergentes, podendo aqui assistir-se ao rápido desenvolvimento de novas indústrias em áreas promissoras (isto é, rentáveis) do conhecimento, inclusive para jovens pesquisadores ou "venture" capitalistas nacionais.

O livro de Marcelo Dias Varella vem contribuir, como o de Tullo Vigevani, para a “internalização” de relevantes questões internacionais - que constituem também questões centrais de nossa política nacional nas áreas industrial e tecnológica - e para a discussão bem informada, por parte do público interessado, de problemas cruciais da inserção econômica externa e das relações internacionais do Brasil. Que eles possam figurar sem demora nas listas de leituras obrigatórias dos cursos especializados e nas bibliografias de todos os estudiosos dos temas aqui discutidos. 